\title{
VOZES DISSONANTES: RESPONSABILIDADE E IMPACTO MÚTUOS ENTRE SOCIEDADE E UNICAMP ${ }^{1}$
}

\author{
Samira Kauchakje ${ }^{2 *}$
}

\section{RESUMO}

O artigo tem por objetivo refletir sobre os desafios, as possibilidades e responsabilidade das universidades brasileiras, em particular, da Unicamp, diante das políticas que sistematicamente têm desestruturado e constrangido tanto instituições públicas, não ancoradas diretamente nos direito sociais, como aquelas que garantem o seu exercício, como é o caso da educação e das instituições de ensino. Para isto são focalizados alguns aspectos do cenário sócio - político brasileiro entre 1970 a 1995 (com o recorte para alguns movimentos sociais do período), contrapondo-os a fragmentos da história da Universidade Estadual de Campinas (UNICAMP). As reflexões têm como pano de fundo a relação mútua e dinâmica entre o movimento da realidade social e as atividades de ensino, pesquisa e extensão, assim como, o ambiente e condições de trabalho nas universidades.

PALAVRAS-CHAVE: Universidade; UNICAMP; Movimentos sociais; Sociedade.

Este artigo pretende relembrar o já bastante e há tempo assumido pressuposto sobre a relação mútua e dinâmica entre o movimento da realidade social e as atividades de ensino, pesquisa e extensão, assim como, o ambiente e condições de trabalho nas universidades ${ }^{3}$.

O objetivo é focalizar alguns aspectos do cenário sócio - político brasileiro entre 1970 a 1995 (com o recorte para alguns movimentos sociais do período), contrapondoos a fragmentos da história da Universidade Estadual de Campinas (UNICAMP).

\footnotetext{
${ }^{1}$ Este trabalho, com algumas modificações, é parte da tese de doutorado: "Movimentos sociais na academia: um olhar sobre as teses e dissertações produzidas na UNICAMP e na USP entre 1970 e 1995”, defendida em 1997 na Faculdade de Educação da UNICAMP.

2 Assistente Social, docente do Curso de Fonoaudiologia e do CEPRE da FCM-Unicamp e Pesquisadora do Grupo de Estudos sobre Movimentos Sociais e Cidadania/ FE-UNICAMP.

${ }^{3}$ Não há a pretensão de repassar a rica discussão sobre a objetividade do conhecimento no campo das Ciências. Discussão presente nas obras de COMTE, DURKHEIM, MARX e WEBER (também em MANNHEIM), para lembrar apenas alguns dos clássicos das Ciências Sociais.
} 
De fato, novas conjunturas e uma efervescência político-social marcaram estes 25 anos e, de alguma forma, as condições para a produção do conhecimento, o ensino, a extensão e as diversas facetas do trabalho no interior das universidades brasileiras acompanharam, sofreram influência e influenciaram este movimento da realidade.

\section{ASPECTOS DO CENÁRIO SÓCIO-POLÍTICO BRASILEIRO (1970-1975)}

A década de 70, sob os governos militares de Médice (1969-1974), Geisel (1974-1979) e Figueiredo (1979-1985), foi um dos momentos de maior centralização e violência por parte do Estado. O regime autoritário e seus vários tentáculos reprimiram e cassaram a cidadania de forma violenta, com a morte, o exílio e a tortura dos que resistiam e insistiam em exercê-la como um direito.

Este período também preparou o caminho para a abertura, resultado das lutas populares, das elites políticas progressistas e das negociações e dissensão entre a própria cúpula do governo de então. O processo de liberalização ocorreu como exigência da sociedade civil e com o planejamento do próprio governo militar. Uma das razões para isto é que o bloco autoritário não era monolítico e as fissuras existentes agravaram-se em meados da década de 70, sugerindo à sociedade civil a oportunidade de algumas formas de organização social. Quando a "repressão cede, seja por que razão for, a primeira reação é uma explosão de organizações autônomas da sociedade civil” (PRZEWORSKI, 1994, p. 82-86). A distensão, portanto, foi conseqüência da dissensão entre os militares e efeito de uma intensa mobilização popular.

É nesta década, por exemplo, que ocorreram os movimentos populares e trabalhistas que simbolizam a luta pela reconquista da cidadania. Os movimentos populares foram organizados em torno, principalmente, da ala progressista da Igreja Católica (ligada à Teologia da Libertação e atuando nas CEBs). Dentre eles destacamos o Movimento do Custo de Vida (MCV, mudando, depois, para MCC - Movimento 
Contra a Carestia), iniciado em 1974 e cujo pico mobilizador foi em 1978. Neste mesmo ano, o movimento operário, que tinha integrantes no movimento popular, passou a ser conhecido dentro e fora do país, a partir das greves no ABC paulista (DOIMO, 1993).

Os “anos 80 iniciaram-se com os movimentos sociais fortalecidos. Recémcriados a partir da conjuntura política brasileira dos anos 70, vários movimentos sociais haviam acabado de dar um salto qualitativo, saindo das reivindicações isoladas para formas mais amplas das demandas em grandes blocos. O movimento sindical cria a Conclat, depois a CUT, a CGT e a USI. O movimento popular cria a CONAM, a ANAMPOS etc” (GOHN, 1991, p. 10).

Em 1984, ocorreu o movimento das Diretas-Já, para que fosse aprovada a emenda Dante de Oliveira, que versava sobre eleições diretas para presidente. Em poucos meses “a Campanha das Diretas empolgou o país e mobilizou milhões de pessoas. Ela colocava na ordem do dia, não só o desejo de parte substancial da população de votar para presidente da República, mas outra vez sua aspiração de conquistar de maneira plena a sua cidadania” (MOISÉS, 1990, p. 31). Apesar do movimento, houve a passagem indireta do governo militar para o civil, com Tancredo Neves assumindo a Presidência. Devido à morte deste, logo após a posse, assume o vice Sarney (1985-1990), ex-senador e membro do partido que apoiava os governos militares. $^{4}$

Somente em 1989, 25 anos depois de instalado o regime militar, a população elegeu diretamente o Presidente da República. Esta eleição trouxe o legado do processo de privatização da coisa pública e de autoritarismo, inscrito no Estado e também na

\footnotetext{
${ }^{4}$ Para Fernandes (1985), o processo de transição "queria dizer simplesmente, que a ditadura não seria desmantelada e que ela serviria de guia a uma democracia sui generis, que sairia das entranhas do regime".
} 
sociedade $^{5}$. A vitória de Collor (42,75\% dos votos) sobre o candidato Lula (do Partido dos Trabalhadores, 37,86\% dos votos) “foi a vitória da elite política tradicional, da elite econômica do setor privado, do capital financeiro, dos setores empresariais ligados à grande e média empresa, dos representantes da Nova Direita _ o que clamam por menos Estado e mais mercado, inclusive aí os representantes do 'agro-busines' moderno e produtivo” (AVELAR, 1994, p. 54).

Em 1988, após um processo constituinte que volta a mobilizar setores organizados da sociedade, é elaborada a nova Constituição. Nela estão inscritos avanços consideráveis em relação aos direitos sociais e políticos, tais como: extensão do sufrágio aos analfabetos; garantias ao movimento sindical (autonomia em relação ao Estado e direito à greve); ampliação e preservação dos direitos à igualdade, de minorias como os portadores de deficiência (acesso a equipamentos de educação e saúde, por exemplo); introdução de mecanismos de participação popular (o referendo, o plebiscito e a iniciativa popular).

Entretanto, como visão geral, para o Brasil e para um grande número de países, esta década foi marcada “por forte recessão econômica, empobrecimento do Estado e de amplas camadas da população” (AVELAR, 1994, p. 53). Inclusive no mundo capitalista desenvolvido, problemas como pobreza, desemprego em massa, miséria e instabilidade, que pareciam ter sido eliminados há uma geração, reapareceram depois de 1973 e, "na década de 80 muitos dos países mais ricos e desenvolvidos se viram outra vez acostumando-se com a visão diária de mendigos nas ruas, e mesmo com o espetáculo

\footnotetext{
${ }^{5}$ Ao dizermos que a sociedade brasileira é autoritária, estamos pensando em "certos traços gerais das relações que se repetem em todas as esferas da vida social (da família ao Estado, passando pelas relações de trabalho, pela escola, pela cultura). Vivemos numa sociedade verticalizada e hierarquizada (embora não o percebamos) na qual as relações sociais são sempre realizadas ou sob a forma da cumplicidade (quando os sujeitos sociais se reconhecem como iguais), ou sob a forma do mando e da obediência entre superior e inferior (quando os sujeitos sociais são percebidos como diferentes, a diferença não sendo vista como assimetria, mas como desigualdade). Não existe no Brasil, a idéia da Revolução Francesa de igualdade de direitos e de igualdade jurídica dos cidadãos. A forma autoritária da relação é marcada por aquilo mesmo que a realiza e a conserva: as relações de favor, tutela e clientela” (CHAUÍ, 1994a).
} 
mais chocante de desabrigados protegendo-se em vãos de portas e caixas de papelão...”. Espetáculo decorrente do aumento da desigualdade social e econômica, em que o candidato a campeão mundial é o Brasil, já denominado, sem exagero, de “monumento de injustiça social” (HOBSBAWN, 1995, p. 396-397).

Sob este impacto, os últimos anos da década anunciaram os primeiros contornos daquilo que seria melhor delineado nos anos 90, ou seja: a descrença nas instituições políticas e um esfriamento das utopias como motores das ações coletivas. Os movimentos sociais brasileiros tenderam a um refluxo, apesar das conquistas e mobilizações dos anos antecedentes, fazendo-nos lembrar que a disposição para a participação não é mantida somente pelas vitórias, mas, sobretudo, pela esperança, isto é, mais do que possíveis derrotas, o que desmobiliza as pessoas e movimentos sociais é, principalmente, a perda da esperança (BERTRAND, 1989).

Em suma, “os movimentos sociais se organizaram, os sindicatos se fortaleceram e as aspirações por uma sociedade mais justa e igualitária ganharam forma na reivindicação de direitos, projetaram-se no cenário público, deixaram suas marcas em conquistas importantes na Constituição de 1988 e se traduziram na construção de sujeitos políticos hoje reconhecidos como interlocutores legítimos no jogo político nacional. Essa década, vivida sob o signo da esperança democrática, encerrou-se, no entanto, com o espetáculo de uma pobreza talvez jamais vista em nossa história republicana. Entramos nos anos 90 vivendo o paradoxo de uma democracia consolidada nas suas instituições e nas regras formais do jogo político, mas que convive cotidianamente com a violência, a violação dos direitos humanos e a incivilidade nas relações sociais” (TELLES, 1994, p. 7).

Neste quadro, a alternativa que mais obteve repercussão, junto à parte da população e à elite política, foi a propagada pelos ideólogos do neoliberalismo. 
Os anos 90 iniciaram sob uma crise de paradigmas, simbolizada pela entrada do capitalismo na antiga União Soviética e pela derrubada do Muro de Berlim (1989), que separava as, até então, Alemanha Ocidental e Oriental. Para Przerworski (1994, p. 22), “aquilo que morreu na Europa Oriental foi a própria idéia de administração racional das coisas para satisfazer às necessidades humanas - a viabilidade de instalar a propriedade pública dos recursos produtivos por intermédio de um controle centralizado; foi o projeto de fundar a sociedade na cooperação desinteressada, a possibilidade de dissociar as contribuições sociais das recompensas individuais.” Já para Furtado (1997a), o “que aconteceu foi a falência do tipo de organização econômica praticada no Leste. Eles tiveram muitas vitórias sociais, mas praticaram uma planificação que só funciona em época de guerra ou de grandes reformas.” Como se confundia socialismo com o Muro de Berlim, que era uma impostura histórica, pagou-se um preço enorme no campo das idéias socialistas”.

A ideologia neoliberal ${ }^{6}$ encontrou campo fértil de disseminação nestas décadas de crise não só econômica e política, mas também social e moral, apregoando a impossibilidade do Estado empreender ações reguladoras da economia e das relações sociais e de trabalho. Por ser "uma ideologia em estado puro, essa tradição acredita na capacidade quase mágica da iniciativa privada” (CHAUÍ, 1992), embora, até mesmo governos que enfatizam a propaganda neoliberal, entre eles os EUA e a Grã-Bretanha, sob a aparência de estimular as forças do mercado, administram e orientam suas economias (HOBSBAWN, 1995).

Contudo, e talvez por isso, os movimentos sociais no Brasil adquirem uma qualidade diferente daquela dos anos anteriores. Entre outras coisas, eles têm um aprendizado de relação com as diversas facetas do Estado, pois, ao longo do tempo, em

\footnotetext{
${ }^{6}$ Ver, por exemplo: SADER (1995); DRAIBE (1993) e Revista USP-Dossiê Liberalismo/Neoliberalismo.
} 
conjunto com a intenção de autonomia, os movimentos sociais, em particular os populares, mantiveram alguma forma de interação com a "institucionalidade política” (DOIMO, 1993, p. 141-142).

Houve, ainda, o envolvimento em dois momentos políticos importantes: em 1992, a deposição do Presidente Collor (em vários pontos do país ocorreu manifestação popular de grande repercussão, com a participação entusiasmada dos estudantes dos segundo e terceiro graus - denominados caras-pintadas, lembrando $o$ movimento pelas diretas) ${ }^{7}$; em 1994, as eleições para a Presidência, Senado e Congresso.

Estas últimas eleições tiveram, à frente da disputa presidencial, os candidatos Lula, Luís Inácio da Silva (Partido dos Trabalhadores) e Fernando Henrique Cardoso (Partido Social Democrata Brasileiro). Os dois candidatos provenientes de meio social, cultural e econômico distintos: o primeiro, líder sindical, presidente do PT e exdeputado federal; o segundo, acadêmico, ex-deputado, ex-senador e ministro da economia do governo imediatamente anterior. Ambos destacaram-se na vida pública por defenderem posições favoráveis às lutas populares. Fernando Henrique Cardoso, todavia, elegeu-se ao lado de figuras de perfil político liberal-conservador que estão no (e em concordância com o) poder desde, pelo menos, a década de 70, e propôs, como diretriz de governo, a política "centro - sinistra” de "aceitar a abertura dos mercados mundiais e lutar para manter ou restabelecer a reintegração da sociedade” (TOURAINE, 1997).

Refletindo estes fatores intrincados estavam em foco os novos movimentos sociais, "centrados mais em questões éticas ou de revalorização da vida humana", (GOHN, 1994, p. 4). Movimentos ligados à questões étnicas, de gênero, geracionais, do

\footnotetext{
${ }^{7} \mathrm{O}$ episódio do impedimento teve também, como protagonistas, além das elites políticas progressistas, as elites conservadoras. "O movimento pelo impeachment do presidente eleito foi orquestrado por uma parcela desta elite insatisfeita com os rumos da política econômica, ressentida com sua não participação nas políticas.” (AVELAR, 1994, p. 54).
} 
meio ambiente, são alguns dos exemplos, com a característica peculiar de que, no Brasil, juntamente com as novas demandas são mantidas as reivindicações por direitos sociais tradicionais: habitação, alimentação, saúde, educação e, também, trabalho_ reivindicações que continuam sendo bastante atuais e prementes.

\section{UNICAMP}

Se entendermos universidade como "comunidade (mais ou menos autônoma) de mestres e alunos reunidos para assegurar o ensino de um determinado número de disciplinas em nível superior”, podemos admitir que as primeiras universidades “surgiram na Europa Ocidental, no início do século XIII”. Neste sentido, a UNICAMP faz parte daquela “aventura intelectual e social iniciada há sete séculos...” (CHARLE,; VERGER, 1996, p. 7-13; p.127).

A Universidade Estadual de Campinas é bastante jovem, embora os primeiros passos para a sua fundação tenham sido dados já na década de 40, com o movimento pela criação da Faculdade de Medicina em Campinas, entrou efetivamente em funcionamento em 19 de dezembro de 1966 e é relevante observar que o início da Universidade coincide com os primeiros anos da ditadura militar no Brasil (período de progressiva perda da autonomia universitária).

Naquela conjuntura as diretrizes da UNICAMP estavam em consonância com o modelo de desenvolvimento econômico adotado no país ${ }^{8}$, isto é, respondia à pressões e interesses estratégicos para o período: “a emergência da UNICAMP em 1966 vinha

\footnotetext{
${ }^{8}$ Para Lima (1989, p. 105), a "adequação da UNICAMP à realidade de seu tempo durante a sua construção, deu-se mediante a sua vinculação competente ao processo de modernização capitalista em curso naquela época...”
} 
satisfazer especialmente aspirações de ordem técnica, industrial e de especialização qualificada” (JORNAL...,1996, n.115).

O “projeto de instalação da UNICAMP veio responder à demanda crescente por pessoal qualificado numa região do Brasil, o estado de São Paulo, que já nos anos 60 detinha $40 \%$ da capacidade industrial e $24 \%$ de sua população ativa.

Até então o sistema de ensino superior estava voltado para a formação de profissionais liberais solicitados pelo processo de urbanização, como advogados, médicos e engenheiros civis. Necessitava-se, portanto, de uma universidade que desse ênfase especial à pesquisa tecnológica e mantivesse desde o início sólida vinculação com o setor produtivo...”(BREVE..., 1996).

Mesmo correspondendo às demandas do período, a UNICAMP garantia a permanência de professores de convicções políticas e opções teóricas diversas, inclusive daqueles que estavam em franco desacordo com os modelos vigentes, tanto de universidade quanto político-econômico. Isto porque ela era uma das poucas universidades brasileiras com "relativa autonomia institucional, apesar de estar sob a égide de um governo e de uma legislação (após 1968) autoritários que cercearam a iniciativa de diversas das Universidades do país em todos os aspectos: político, financeiro, administrativo e acadêmico”. A autonomia e a liberdade na UNICAMP eram, entretanto, relativas e “consentidas”, uma vez que deviam muito às características pessoais e ao prestígio que Zeferino Vaz, reitor na época, gozava junto às autoridades de então (MENEGUEL, 1994, p. 112; p. 157).

Com a dinâmica da vida universitária e do meio social, o modelo tecnocrático foi expandido para outras direções, em particular, para a Economia e para as Ciências Sociais, como demonstra a cronologia da criação de suas Faculdades e Institutos: 
inicialmente foi privilegiada a consolidação dos Institutos de Ciências Básicas (Física, Química e Matemática); em seguida, as Faculdades de Engenharia (Elétrica, Mecânica, Química, Civil, de Alimentos e Agrícola), juntamente com o fortalecimento dos cursos de Medicina, Biologia e Odontologia, já existentes; após isto, o desenvolvimento dos cursos de Filosofia, Ciências Sociais, Economia, Lingüística e Literatura e, finalmente, a criação dos cursos na área de Artes (exceto de Música, que existia anteriormente).

A UNICAMP construiu sua identidade, principalmente, através das atividades de pesquisa e dos cursos de pós-graduação. Isto pode ser traduzido por números, (dados do SIARQ/UNICAMP; do Relatório do Biênio-96 e; da Folha de São Paulo de 05.10.96): tem uma área física de 2.949.399m2 (área construída: 403.740 m2); conta com cerca de 2.000 professores (aproximadamente $80 \%$ deles com titulação mínima de Doutor); responde por, aproximadamente, $15 \%$ de toda a produção científica nacional; concentra, sozinha, $12 \%$ dos estudantes brasileiros de Mestrado e Doutorado; concentra, ainda, 7\% do corpo docente de pós-graduação do país.É importante, todavia, não correr o risco de congelar esta imagem, seja em sua história passada ou recente. Nos anos 90 uma série de medidas governamentais, sistematicamente tem desestruturado e constrangido tanto instituições públicas, não ancoradas diretamente aos direito sociais, como aquelas que garantem o seu exercício, como é o caso da educação e das instituições de ensino.

As universidades vêem-se diante da proposta e da atuação homogeneizante dos ideólogos do neoliberalismo. Esta ideologia que logrou ser hegemônica não considera as características peculiares de cada instituição de ensino (ou realidade social), mas intervém com um receituário monótono e repetitivo para todas as políticas públicas: “desregulamentação das atividades econômicas e sociais, baseada na superioridade da 
‘eficiência do mercado’ em relação ao ‘burocratismo’ do Estado” e “particularização dos benefícios sociais”9 (FERNANDES, 1995), enfim, a “deserção”10 do Estado.

Neste sentido, lembramos Chauí (1994b, p. 51-54) que ao rever a história da USP desde os anos 60, traz elementos para a compreensão de outras importantes universidades brasileiras. A autora observa que "um curioso tecido surge diante de nós. Os anos 60 sonharam com a revolução social que teria na universidade pública (a universidade crítica, como a chamávamos), uma de suas principais frentes de luta. Os anos 70, silenciando a universidade crítica, deixaram realizar o sonho de ascensão social da classe média da ditadura, destruindo a qualidade do ensino público em todos os graus, na alegria da massificação. Os anos 80 acreditaram numa universidade autônoma e democrática, capaz de equilibrar as exigências do rigor acadêmico e as demandas de uma sociedade marcada pela carência, pela miséria e pela violência. Os anos 90 tornaram-se prosaicamente realistas: do lado das associações docentes, estudantis e de funcionários, o discurso está centrado na idéia de interesse de categorias, enquanto do lado das direções universitárias prevalece o discurso de eficiência, produtividade $e$ competitividade, associado à imagem de ligação umbilical entre os interesses da sociedade civil e da pesquisa, isto é, os interesses do mercado”.

E a autora fornece argumentos sobre as implicações mais radicais deste intercâmbio, pois, quando “as pesquisas são financiadas por empresas e organismos privados (...) finalidades e resultados dos trabalhos não são públicos, no duplo sentido do termo, isto é, não têm origem pública e não são publicizados”. Esta relação é comumente vista como "modelo de modernidade porque desincumbe o poder público da

\footnotetext{
${ }^{9}$ Apesar da citação usar o termo "benefício social”, estamos trabalhando aqui com o conceito de direito que se "diferencia de uma carência, de um privilégio e de um interesse. Carência e privilégio são, por definição, particulares e específicos (....).Direitos são universais, seja porque são os mesmos para todos, seja porque são universalmente reconhecidos quando explicitam diversidades (de gênero, religião, etnia, sexualidade etc)” (CHAUÍ, 1994b, p. 64).

10 Sobre a noção de “Estado desertor”, ver AGUILAR (1994).
} 
responsabilidade com os custos da pesquisa e recebe o nome de cooperação entre a universidade e a sociedade civil”.

As respostas das universidades brasileiras a estas pressões podem significar acordo, sujeição ou reação, indicando a diretriz de seu desenvolvimento no futuro próximo, pois, se o impacto e confronto com a realidade social molda, impõe restrições, modifica e amplia o perfil das universidades, esta inserção tem uma contrapartida, isto é, o contexto social também sofre a influência das atividades das universidades.

Em diferentes cenários sócio-políticos, os movimentos sociais são exemplos paradigmáticos de vozes que destoam e colocam novas questões. E nestes tempos de discursos uníssonos e ações, em grande parte, homogêneas, inspirados no “fundamentalismo do livre mercado” (HOBSBAWN, 2000), também as universidades e, em nosso caso, a UNICAMP (leia-se administradores, docentes, alunos e funcionários) podem reverter tendências, colocando-se como “vozes dissonantes”.

\section{REFERÊNCIAS BIBLIOGRAFICAS}

AGUILAR, L. E. O Estado desertor: Brasil e Argentina nos anos de 1982-1992. 1994. Tese (Doutorado) - Faculdade de Educação, Universidade Estadual de Campinas, Campinas.

AVELAR, L. Mudanças estruturais, crise política e eleições. São Paulo em Perspectiva Revista SEADE, São Paulo, v. 8, n. 2, abr.jun. 1994.

BERTRAND, M. Elementos para uma teoria marxista da subjetividade. In: SILVEIRA, P. (Org.).São Paulo: Vértice, 1989.

BREVE GUIA SOBRE A UNICAMP. Campinas: UNICAMP, 1996.

CHARLE, C.; VERGER, J. História das universidades. São Paulo: Editora UNESP, 1996.

CHAUÍ, M. Cidadania Cultural em Ação 1989-1992. Prestação de contas da Secretaria Municipal da Cultura aos cidadãos. São Paulo, SMC, 1992. 
Raízes teológicas do populismo no Brasil: teocracia dos dominantes

messianismo dos dominados. In: DAGNINO, E. (Org.). Anos 90: política e sociedade no Brasil. São Paulo: Brasiliense, 1994a.

USP 94: a terceira fundação. Estudos Avançados, São Paulo, v. 8, n. 2, p. , set./dez. 1994b.

DOIMO, A. M. Movimento popular no Brasil pós-70: formação de um campo ético político. 1993. Tese (Doutorado) - Faculdade de Letras e Ciências Humanas, Universidade Estadual de São Paulo, São Paulo.

DRAIBE, S. As políticas sociais e o neoliberalismo. Revista USP Dossiê

Liberalismo/Neoliberalismo, São Paulo, n. 17, mar./maio. 1993.

FERNANDES, F. Nova República?. São Paulo: Ática, 1985.

FERNANDES, L. Neoliberalismo e reestruturação capitalista. In: SADER, E. (Org.).

Pós - Neoliberalismo: as políticas sociais e o estado democrático. São Paulo: Paz e

Terra, 1995.

FURTADO, C. Mundo do amanhã. Veja, São Paulo, ano 30, n.1, 8 jan.1997.

GOHN, M. G. Novos movimentos sociais e a construção da cidadania: balanço dos anos 80 e tendências nos anos 90. São Paulo, 1994. Mimeografado.

Movimentos sociais e luta pela moradia. São Paulo: Loyola, 1991.

HOBSBAWN, E. J. Era dos extremos: o breve século XX: 1914-1991. São Paulo:

Companhia das Letras, 1995.

O novo século: entrevista a Antonio Polito. São Paulo: Companhia das Letras, 2000.

JORNAL DA UNICAMP. Campinas, ano X, n. 115, out. 1996.

LIMA, E. J. S. A criação da UNICAMP: administração e relações de poder numa perspectiva histórica. 1989. Dissertação (Mestrado) - Faculdade de Educação, Universidade Estadual de Campinas. Campinas.

MENEGHEL, S. M. Zeferino Vaz e a UNICAMP: uma trajetória e um modelo de Universidade. 1994. Dissertação (Mestrado) - Faculdade de Educação, Universidade Estadual de Campinas. Campinas.

MOISÉS, J. A. Cidadania e participação: ensaio sobre o plebiscito, o referendo e a iniciativa popular na nova Constituição. São Paulo, CEDEC, 1990.

PRZEWORSKI, A Democracia e mercado: no Leste Europeu e na América Latina.

Rio de Janeiro, Relume Dumará, 1994. 
UNIVERSIDADE ESTADUAL DE CAMPINAS. Relatório do Biênio: abr. 1994-abr. 1996. Campinas

REVISTA USP. Dossiê Liberalismo/Neoliberalismo. n. 17, mar./maio 1993.

SADER, E. (Org.). Pós-neoliberalismo: as políticas sociais e o estado democrático. São Paulo: Paz e Terra, 1995.

TELLES, V. Sociedade Civil e os caminhos (incertos) da cidadania. São Paulo em Perspectiva. Revista SEADE, São Paulo, v. 8, n. 2, abr./jun. 1994.

TOURAINE, A A trajetória de FH e os caminhos do país. O Estado de São Paulo, São Paulo, 16 jan. 1997. p. d4. 